\title{
Safety and Efficacy of Chemotherapy Combined with Anlotinib Plus Anlotinib Maintenance in Chinese Patients with Advanced/Metastatic Soft Tissue Sarcoma
}

This article was published in the following Dove Press journal: OncoTargets and Therapy

\section{Hai-ying Wang \\ Jun-feng Chu \\ Peng Zhang \\ jia-qiang Wang \\ Zheng Yan \\ Shu-na Yao \\ Zhi-hua Yao \\ Yan-yan Liu}

Department of Internal Medicine, Affiliated Cancer Hospital of Zhengzhou University, Henan Cancer Hospital,

Zhengzhou, Henan, People's Republic of China
Correspondence: Zhi-hua Yao; Hai-ying Wang

Department of Internal Medicine, Affiliated Cancer Hospital of Zhengzhou University, Henan Cancer Hospital, No. I 27 Dongming Road, Zhengzhou, Henan 450008, People's Republic of China

$\mathrm{Tel} / \mathrm{Fax}+86$ 37I-6558779I;

+86 I3838326280

Email happierzhihua@126.com;

470242877@qq.com
Purpose: Anlotinib, a newly developed oral small-molecule receptor tyrosine kinase inhibitor (TKI), has been shown to have encouraging activity against sarcoma. The purpose of this study was to retrospectively evaluate the safety and clinical efficacy of chemotherapy combined with anlotinib plus anlotinib maintenance in advanced/metastatic soft tissue sarcoma (STS) patients in a real-world setting in China.

Patients and Methods: We retrospectively collected the medical data of thirty-two patients with advanced/metastatic STS who received chemotherapy combined with anlotinib plus anlotinib maintenance therapy. The objective response rate (ORR) and disease control rate (DCR) were calculated according to the RECIST 1.1 criteria. The progression-free rates (PFRs) at three and six months, the progression-free survival (PFS) time, and adverse events were recorded.

Results: On the basis of investigator assessments, two patients $(6 \%)$ achieved CR (complete response) and nine patients (28\%) achieved PR (partial response), with an ORR of 34\%. Eleven patients (34\%) achieved SD (stable disease), and ten patients (31\%) achieved PD (progression disease), with a DCR of $69 \%$. The progression-free rates (PFRs) at three and six months were $81 \%$ and $69 \%$, respectively. The median PFS time was 8.2 months. The hematologic and non-hematologic toxicities were manageable. The most common grade 3 and 4 adverse events were febrile neutropenia (9\%), leukopenia (19\%), thrombocytopenia $(3 \%)$, anemia $(6 \%)$, anorexia $(6 \%)$, vomiting $(3 \%)$, and hypertension $(6 \%)$. The combination therapy was generally well tolerated.

Conclusion: Our study suggests that chemotherapy combined with anlotinib plus anlotinib maintenance therapy had good efficacy and resulted in more favorable survival with good tolerance among patients with advanced/metastatic STS.

Keywords: advanced/metastatic soft tissue sarcoma, anlotinib, chemotherapy, toxicity

\section{Introduction}

Soft tissue sarcomas (STSs) are a heterogeneous type of solid tumor that originates from mesenchymal tissue. ${ }^{1}$ STSs, which are divided into more than 50 types by The World Health Organization (WHO), account for approximately $1 \%$ of adult malignant tumors and $15 \%$ of pediatric malignant tumors. ${ }^{2}$ The main treatments for STS are surgery, radiotherapy and chemotherapy. Although STS has a low incidence, it is extremely harmful, and there is a high possibility of metastasis and recurrence. ${ }^{3}$ 
STS usually metastasizes to the lungs, and abdominal soft tissue sarcomas usually metastasize to the peritoneum or liver. ${ }^{4}$ For advanced soft tissue sarcoma patients who have lost the chance of surgery, chemotherapy is the main method of prolonging survival. ${ }^{5}$ The conventional firstline treatment for advanced STS is either doxorubicin as monotherapy or in combination with ifosfamide; the objective response rate is $25 \sim 30 \%$, and the median overall survival time is approximately $12-17$ months. ${ }^{6}$ Response rates increase with higher doses of chemotherapy drugs, however at the cost of a worse safety profile and no increase in OS. Because of the limited benefits seen from current treatments, there is an urgent clinical need for therapies with improved survival and safety. ${ }^{7}$

Tumor angiogenesis is an important process in tumorigenesis and metastasis for STS. Thus, anti-angiogenic treatments are important for the control of soft tissue sarcoma. ${ }^{8}$ Some new drugs for STS have been explored and used in preclinical studies and clinical trials. ${ }^{9-11}$ Anlotinib was developed by China as a new oral multitargeted receptor TKI. Anlotinib inhibits vascular endothelial growth factor/vascular endothelial growth factor receptor (VEGF/VEGFR) signaling by targeting VEGFR1/ $2 / 3$ and FGFR1/2/3/4 with high affinity. Furthermore, it suppresses the activity of platelet-derived growth factor receptor $\alpha$ and $\beta$, c-Kit and RET, resulting in significant inhibition of tumor proliferation in preclinical studies. ${ }^{12-14}$ Anlotinib has encouraging antitumor effects and acceptable toxicity in advanced lung adenocarcinoma, lung squamous cell carcinoma, STS, medullary thyroid cancer, small cell lung cancer and metastatic renal clear cell cancer. ${ }^{15-18}$ A Phase II clinical trial showed that a total of 166 relapsed advanced STS patients had a significant survival benefit after treatment with anlotinib, with a 12 -week progressionfree rate of $68.42 \%$ and an objective response rate of $12.65 \%$. The PFS and OS were 5.63 and 12.33 months, respectively. ${ }^{10}$ The findings from a phase IIb, placebocontrolled trial including 233 patients with recurrent advanced STS showed that anlotinib compared with a placebo significantly prolonged progression-free survival by 4.8 months (6.27 months vs 1.47 months, $\mathrm{P}<0.0001)$. In that study, the ORR $(10.13 \%$ vs $1.33 \%, \mathrm{P}=0.0145)$ and DCR $(55.7 \%$ vs $22.67 \%, \mathrm{P}<0.0001)$ were also significantly improved, but the overall survival data have not been published.

Although these results are encouraging, the outcome is still not satisfactory. Therefore, it is appropriate to attempt adding anlotinib to chemotherapy to determine whether the combination can further improve the efficacy of the treatment; furthermore, the adverse reactions to anlotinib are mild, and the toxicities of the two therapies are different. Preclinical studies have shown that anti-angiogenic drugs combined with cytotoxic chemotherapy constitute an effective method of overcoming drug resistance to chemotherapy drugs and inhibiting tumor growth. ${ }^{19-21}$ Moreover, many clinical data also suggest that the addition of anti-angiogenic drugs to conventional chemotherapy may result in more effective treatment for advanced nonsquamous NSCLC, ${ }^{22}$ colon cancer, ${ }^{23}$ renal cancer, ${ }^{24}$ ovarian cancer $^{25}$ and STS. ${ }^{26}$

Therefore, a retrospective single-center analysis was conducted to evaluate the efficacy and safety and to describe the use of anlotinib combined with chemotherapy in clinical practice in patients with different histological subtypes of advanced STS.

\section{Materials and Methods}

\section{Patient Characteristics}

Data from advanced STS patients at the Affiliated Cancer Hospital of Zhengzhou University were analyzed in this retrospective study. Advanced STS patients who received anlotinib combined with chemotherapy were included. If the STS did not progress after 2-6 cycles of combination therapy, then the patient received maintenance therapy with anlotinib. Other inclusion criteria were an ECOG performance status of $0-2$, histologically confirmed advanced/ metastatic STS, age between 10 and 70 years and adequate bone marrow, liver and kidney functions. From April 2018 to September 2019, a total of 32 advanced/metastatic STS patients were included in the retrospective study.

The clinical variables collected were sex, age, history of surgery, history of radiotherapy, chemotherapy, median number of treatment cycles, treatment toxicities and dose reductions. Absolute neutrophil counts, white blood cell counts, platelet counts and hemoglobin levels were recorded before and after each cycle. We also recorded changes in total bilirubin, transaminase, creatinine, and triglyceride levels; proteinuria; thyroid function; and hypertension. Before the combination treatment was administered, written informed consent was obtained from all patients.

\section{Treatment Methods}

Advanced STS patients received anlotinib plus chemotherapy. If the STS did not progress after 2-6 cycles of combination therapy, the patient received maintenance 
therapy with anlotinib. Anlotinib was initially administered orally at a dosage of $12 \mathrm{mg}$ or $10 \mathrm{mg}$ daily for 14 days and then discontinued for 7 days ( 3 -week cycle). The clinicians determined the initial drug dose of anlotinib depending on the patient's condition.

\section{Safety and Outcome Assessment}

The therapeutic effect was evaluated according to the Response Evaluation Criteria in Solid Tumors (RECIST 1.1) criteria by computed tomography scans every two cycles. The disease control rate (DCR) was defined as the total percentage of patients with stable disease (SD), a partial response (PR) and a complete response (CR). PFS was defined from the beginning of combination treatment to tumor progression or death from any cause. In addition, treatment-related adverse events were assessed according to the Common Terminology Criteria for Adverse Events (CTCAE) version 4.03.

\section{Statistical Analysis}

Data were analyzed with SPSS software (version 14.0). The descriptive variables regarding treatment-related toxicities and patient characteristics were directly calculated from the database. The median PFS was calculated using the Kaplan-Meier method.

\section{Ethics}

This study was approved by the Ethics Committee of Henan Cancer Hospital. All procedures performed in studies involving human participants were in accordance with the ethical standards of the institutional and/or national research committee and with the Helsinki declaration. The informed consent form was waived as this is a retrospective study. The patient data used in the study were confidential.

\section{Results}

\section{Patient Characteristics}

The baseline characteristics of the advanced STS patients, including sex, age, histological subtypes, ECOG performance status, radiotherapy history, surgery history, chemotherapy history, are summarized in Table 1. Seventeen patients were male, and fifteen were female, with an average age of 45 years (range: 15-69 years). The pathological types were liposarcoma (LPS), synovial sarcoma (SS), leiomyosarcoma (LMS), undifferentiated pleomorphic sarcoma (UPS), fibrosarcoma (FS), embryonal rhabdomyosarcoma
Table I Patient Demographics and Clinical Characteristics

\begin{tabular}{|c|c|c|}
\hline Baseline Characteristics & $\begin{array}{l}\text { Number of } \\
\text { Patients (32) }\end{array}$ & $\begin{array}{l}\text { Percentage } \\
\text { (\%) }\end{array}$ \\
\hline $\begin{array}{l}\text { Age (years) } \\
\text { Median } \\
\text { Range }\end{array}$ & $\begin{array}{l}45 \\
15-69\end{array}$ & \\
\hline $\begin{array}{l}\text { Sex } \\
\text { Male } \\
\text { Female }\end{array}$ & $\begin{array}{l}17 \\
15\end{array}$ & $\begin{array}{l}53 \\
47\end{array}$ \\
\hline $\begin{array}{l}\text { ECOG performance status } \\
0 \\
1 \\
2\end{array}$ & $\begin{array}{l}14 \\
17 \\
1\end{array}$ & $\begin{array}{l}44 \\
53 \\
3\end{array}$ \\
\hline $\begin{array}{l}\text { Histology } \\
\text { UPS } \\
\text { LPS } \\
\text { LMS } \\
\text { SS } \\
\text { FS } \\
\text { ERMS } \\
\text { PNET/ES } \\
\text { AS }\end{array}$ & $\begin{array}{l}6 \\
4 \\
6 \\
4 \\
2 \\
5 \\
3 \\
2\end{array}$ & $\begin{array}{l}19 \\
12 \\
19 \\
12 \\
6 \\
16 \\
10 \\
6\end{array}$ \\
\hline $\begin{array}{l}\text { Treatment lines of anlotinib } \\
\text { combination therapy } \\
\text { First line } \\
\text { Second line } \\
\text { Third line }\end{array}$ & $\begin{array}{l}8 \\
12 \\
12\end{array}$ & $\begin{array}{l}25 \\
37.5 \\
37.5\end{array}$ \\
\hline $\begin{array}{l}\text { Anlotinib dose } \\
\qquad 12 \mathrm{mg} \\
10 \mathrm{mg}\end{array}$ & $\begin{array}{l}29 \\
3\end{array}$ & $\begin{array}{l}91 \\
9\end{array}$ \\
\hline $\begin{array}{l}\text { Radiotherapy history } \\
\text { Yes } \\
\text { No }\end{array}$ & $\begin{array}{l}12 \\
20\end{array}$ & $\begin{array}{l}38 \\
62\end{array}$ \\
\hline $\begin{array}{l}\text { Surgery history } \\
\text { Yes } \\
\text { No }\end{array}$ & $\begin{array}{l}30 \\
2\end{array}$ & $\begin{array}{l}94 \\
6\end{array}$ \\
\hline $\begin{array}{l}\text { Chemotherapy history } \\
\text { Yes } \\
\text { No }\end{array}$ & $\begin{array}{l}26 \\
6\end{array}$ & $\begin{array}{l}81 \\
19\end{array}$ \\
\hline
\end{tabular}

Abbreviation: ECOG, Eastern Cooperative Oncology Group.

(ERMS), primitive neuroectodermal tumor/Ewing sarcoma (PNET/ES) and angiosarcoma (AS). A total of $94 \%$ patients (30/32) had a surgical history, and 38\% (12/32) patients with prior use of radiotherapy. A total of 32 STS patients underwent treatment with anlotinib combined with chemotherapy. There were 8 patients (25\%) for whom this was the first-line treatment, 13 patients (41\%) for whom this was a second-line 
treatment, and 11 patients (34\%) for whom this was a thirdline treatment. Twenty-nine patients (29/32.91\%) received $12 \mathrm{mg}$ of anlotinib as the initial dose, and 3 patients (3/ $32.9 \%$ ) received $10 \mathrm{mg}$ anlotinib as the starting dose for 14 days, followed by discontinuation of anlotinib administration for 7 days (3-week cycle). The chemotherapy regimens were based on anthracyclines and ifosfamide, and other drugs included dacarbazine, gemcitabine, docetaxel, temozolomide, vincristine, and cyclophosphamide every 21 days.

Among them, 30 non-progressive STS patients received anlotinib maintenance therapy after $2-6$ cycles of combined treatment. AEs were collected for all patients.

\section{Efficacy}

The median number of cycles administered to the 32 advanced STS patients was four (range: 2-6). A total of two patients $(6 \%)$ achieved $\mathrm{CR}$ and nine patients $(28 \%)$ achieved PR with an ORR of 34\%. Eleven patients (34\%) archived SD, and ten patients (31\%) achieved PD with a DCR of $69 \%$ (Table 2).

Among those receiving this combination therapy as a first-line treatment, the ORR was 50\%, and the DCR was 75\% (2 CR, 2 PR, $2 \mathrm{SD}$, and 2PD). Among those for whom it was the second-line treatment, the ORR was $33.3 \%$, and the DCR was 75\% (4 PR, 5 SD, and 3 PD). Among the patients for whom the combination therapy was the third-line treatment, the ORR was $25 \%$, and the DCR was 58.3\% (3 PR, 4 SD, and 5 PD). The median follow-up period was 14 months. The progression-free rates (PFRs) at three and six months were $81 \%$ and $69 \%$,

Table 2 Overall Response to Treatment

\begin{tabular}{|l|l|l|}
\hline \multirow{2}{*}{ Tumor Response } & \multicolumn{2}{|l|}{ Anlotinib plus chemotherapy (n =32) } \\
\cline { 2 - 3 } & No. & $\%$ \\
\hline Complete response & 2 & 6 \\
\hline Partial response & 9 & 28 \\
\hline Stable disease & 11 & 34 \\
\hline Progressive disease & 10 & 31 \\
\hline RR & 11 & 34 \\
DCR & 22 & 69 \\
Median PFS & 8.2 months & 81 \\
PFR 3 months & & 69 \\
PFR 6 months & & \\
\hline
\end{tabular}

Abbreviations: PR, partial response; SD, stable disease; PD, progressive disease; $R R$, response rate; DCR, disease control rate; PFS, progression free survival; PFR, progression-free rate. respectively (Table 2). The median PFS time for treated patients was 8.2 months (Figure 1; 95\% CI: 5.4-10.6). The median OS was not achieved by the time of analysis.

As shown in Table 3, the histologic subtypes of the responders were as follows: undifferentiated pleomorphic sarcoma $(\mathrm{n}=3,50 \%)$, liposarcoma $(\mathrm{n}=0,0 \%)$, leiomyosarcoma $(\mathrm{n}=3,50 \%)$, synovial sarcoma $(\mathrm{n}=1,25 \%)$, fibrosarcoma $(\mathrm{n}=0,0 \%)$, embryonal rhabdomyosarcoma $(\mathrm{n}=2,40 \%)$, primitive neuroectodermal tumor/Ewing sarcoma $(\mathrm{n}=2,66.7 \%)$ and angiosarcoma $(\mathrm{n}=0,0 \%)$. The disease control rates for the histologic subtypes were as follows: undifferentiated pleomorphic sarcoma $(\mathrm{n}=4$, $66.7 \%)$, liposarcoma $(n=2,50 \%)$, leiomyosarcoma $(n=5$, $83.3 \%)$, synovial sarcoma $(\mathrm{n}=3,75 \%)$, fibrosarcoma $(\mathrm{n}=$ 1, 50\%), embryonal rhabdomyosarcoma ( $\mathrm{n}=3,60 \%)$, primitive neuroectodermal tumor/Ewing sarcoma $(\mathrm{n}=3$, $100 \%$ ) and angiosarcoma (AS) ( $\mathrm{n}=1,50 \%)$ (Table 3$)$.

\section{Adverse Events}

The common treatment-related adverse events are shown in Table 4. The most common grade 3 and 4 adverse events were febrile neutropenia $(n=3,9 \%)$, leukopenia $(\mathrm{n}=6,19 \%)$, thrombocytopenia $(\mathrm{n}=1,3 \%)$, anemia $(\mathrm{n}=$ $2,6 \%)$, anorexia $(\mathrm{n}=2,6 \%)$, vomiting $(\mathrm{n}=1,3 \%)$, and hypertension $(\mathrm{n}=2,6 \%)$ (Table 4$)$. The hematologic and non-hematologic toxicities were manageable, and the incidence of toxicities was similar to that in a prior report of advanced STS chemotherapy.

The most frequent adverse events of anlotinib maintenance therapy were hypertension, hand-foot skin reaction, triglyceride level elevation, hypothyroidism, proteinuria and fatigue. The toxicity profile was generally consistent with that in a prior report of anlotinib in a phase I/II study. No patients stopped treatment with anlotinib due to side effects during maintenance therapy. Moreover, no treatment-related deaths occurred. The combination was generally well tolerated.

\section{Discussion}

STSs in general are relatively insensitive to chemotherapy compared to tumors of epithelial origin. The prognosis of advanced STS patients is still poor, with a median OS in range of $12-17$ months. ${ }^{6,27}$ When patients experience failure of first-line chemotherapy, there is currently no standard second-line treatment option in China, and there are few therapeutic drugs available. ${ }^{28}$ Anlotinib not only inhibits tumor cell proliferation but also inhibits tumor angiogenesis and has been shown to have antitumor 


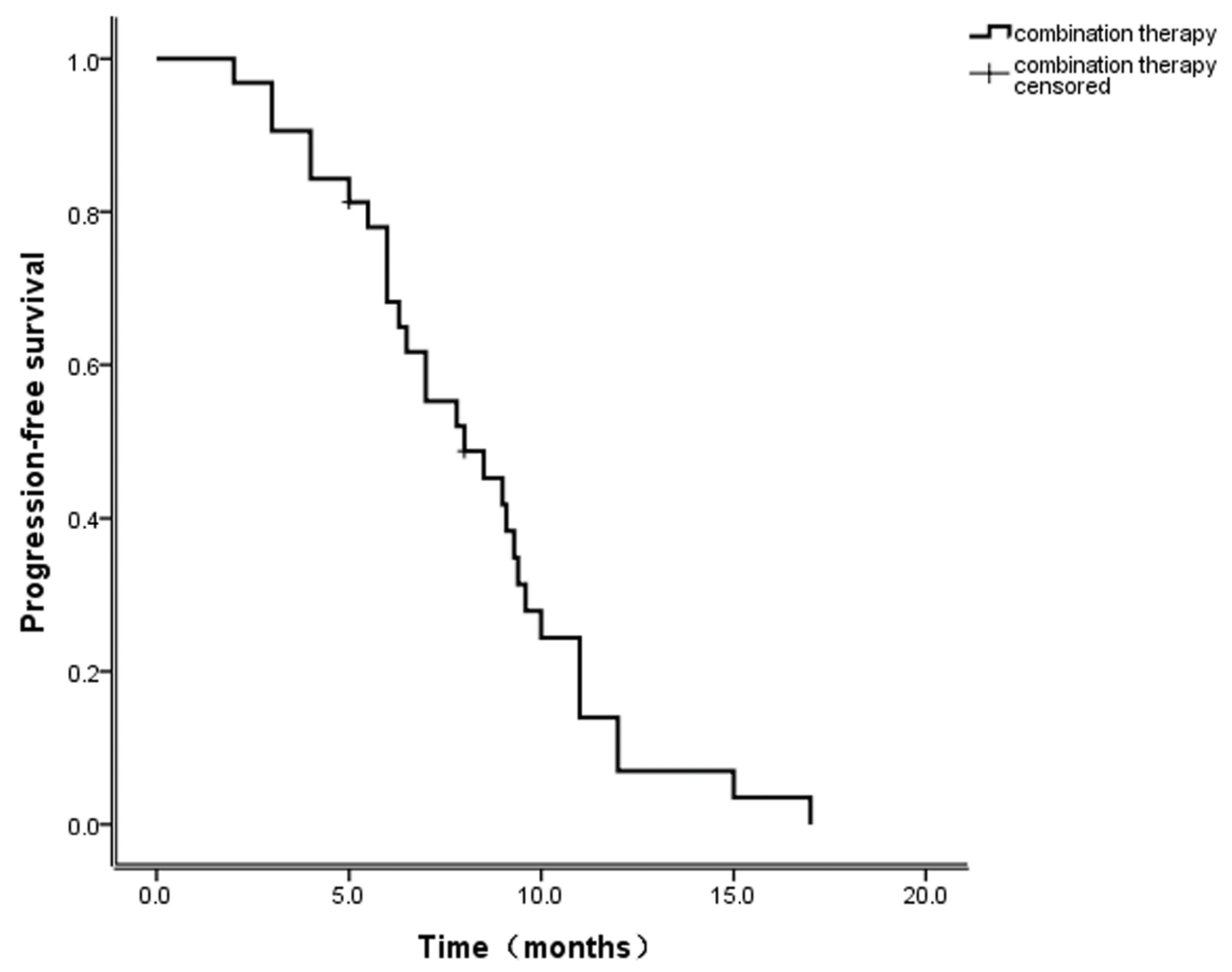

Figure I Progression-free survival.

activity in advanced STS. ${ }^{29}$ In addition, anlotinib has been approved as a second-line treatment for advanced/metastatic STS by the China Food and Drug Administration in 2019.

Preclinical studies have provided strong evidence that the use of anti-angiogenic agents can promote tumor vascular normalization, thereby improving drug delivery and

Table 3 Efficacy Data by Histologic Category

\begin{tabular}{|l|l|l|l|l|}
\hline \multirow{2}{*}{$\begin{array}{l}\text { Histology } \\
\text { Category }\end{array}$} & \multicolumn{4}{|l|}{ Total (n= 32) } \\
\cline { 2 - 5 } & $\begin{array}{l}\text { CR No. } \\
\text { (\%) }\end{array}$ & $\begin{array}{l}\text { PR No. } \\
\text { (\%) }\end{array}$ & $\begin{array}{l}\text { SD No. } \\
\text { (\%) }\end{array}$ & $\begin{array}{l}\text { PD No. } \\
\text { (\%) }\end{array}$ \\
\hline UPS & $\mathrm{I}(16.7)$ & $2(33.3)$ & $\mathrm{I}(16.7)$ & $2(33.3)$ \\
LPS & $0(0.0)$ & $0(0.0)$ & $2(50.0)$ & $2(50.0)$ \\
LMS & $\mathrm{I}(16.7)$ & $2(33.3)$ & $2(33.3)$ & $\mathrm{I}(16.7)$ \\
SS & $0(0.0)$ & $\mathrm{I}(25.0)$ & $2(50.0)$ & $\mathrm{I}(25.0)$ \\
FS & $0(0.0)$ & $0(0.0)$ & $\mathrm{I}(50.0)$ & $\mathrm{I}(50.0)$ \\
ERMS & $0(0.0)$ & $2(40.0)$ & $\mathrm{I}(20.0)$ & $2(40.0)$ \\
PNET/ES & $0(0.0)$ & $2(66.7)$ & $\mathrm{I}(33.3)$ & $0(0.0)$ \\
AS & $0(0.0)$ & $0(0.0)$ & $\mathrm{I}(50.0)$ & $\mathrm{I}(50.0)$ \\
Total & $2(6.2)$ & $9(28.1)$ & $\mathrm{II}(34.4)$ & $\mathrm{I} 0(3 \mathrm{I} .3)$ \\
\hline
\end{tabular}

Abbreviations: UPS, undifferentiated pleomorphic sarcoma; LPS, liposarcoma; LMS, leiomyosarcoma; SS, synovial sarcoma; FS, fibrosarcoma; ERMS, embryonal rhabdomyosarcoma; PNET/ES, primitive neuroectodermal tumor/Ewing sarcoma; AS, angiosarcoma. efficacy in many solid tumors, including STS. Over the past decade, a number of clinical studies have shown that bevacizumab combined with chemotherapy significantly prolongs PFS and OS compared to chemotherapy alone for advanced NSCLC and colon, ovarian, and renal cancers. ${ }^{22}$ Verschraegen $\mathrm{CF}^{26}$ reported a Phase I trial that

Table 4 Toxicity Profile

\begin{tabular}{|l|l|l|l|}
\hline Toxicity & $\begin{array}{l}\text { Total No. } \\
\text { (\%) }\end{array}$ & $\begin{array}{l}\text { I + II No. } \\
\text { (\%) }\end{array}$ & $\begin{array}{l}\text { III+ IV No. } \\
\text { (\%) }\end{array}$ \\
\hline Leukopenia & $22(69)$ & $16(50)$ & $6(19)$ \\
Febrile neutropenia & $9(28)$ & $6(19)$ & $3(9)$ \\
Thrombocytopenia & $4(12)$ & $3(9)$ & $1(3)$ \\
Anemia & $19(59)$ & $17(53)$ & $2(6)$ \\
Anorexia & $16(50)$ & $14(44)$ & $2(6)$ \\
Nausea/vomiting & $14(44)$ & $13(4 I)$ & $1(3)$ \\
Diarrhea & $3(9)$ & $3(9)$ & $0(0)$ \\
Hypertension & $8(25)$ & $6(19)$ & $2(6)$ \\
Fatigue & $12(38)$ & $12(38)$ & $0(0)$ \\
Hand-foot skin reaction & $2(6)$ & $2(6)$ & $0(0)$ \\
Triglyceride elevation & $8(25)$ & $8(25)$ & $0(0)$ \\
Proteinuria & $7(22)$ & $7(22)$ & $0(0)$ \\
ALT elevation & $9(28)$ & $9(28)$ & $0(0)$ \\
AST elevation & $8(25)$ & $8(25)$ & $0(0)$ \\
Hypothyroidism & $5(16)$ & $5(16)$ & $0(0)$ \\
\hline
\end{tabular}


showed that bevacizumab combined with docetaxel and gemcitabine in 36 patients with advanced/metastatic STS had an ORR of $31 \%$, including 4 CR, 6 PR, and 18 SD. In addition to the angiogenic pathway, factors in proliferative pathway, such as PDGF and c-Kit, are also likely to contribute to the high malignancy of STS. ${ }^{13}$ Reported by the Spanish sarcoma study group, a prospective randomized phase II study in 35 advanced STS patients received sorafenib combined with ifosfamide, which proved to be a promising therapy, with three-month and six-month PFS rates of $66 \%$ and $37 \%$, a median PFS time of 4.8 months, and a OS time of 16.2 months. ${ }^{30}$ A prospective phase II clinical study is ongoing to evaluate the safety and effectiveness of anlotinib combined with epirubicin and ifosfamide in the treatment of metastatic or advanced soft tissue sarcomas. Therefore, the combination of chemotherapy with other antiangiogenic active drugs may lead to better efficacy for advanced STS.

Thus far, this is the first study of chemotherapy combined with anlotinib for advanced STS patients. In this study, a total of two patients $(6 \%)$ achieved CR and nine patients (28\%) achieved PR, with an ORR of 34\%. Eleven patients (34\%) achieved SD, and ten patients $(31 \%)$ achieved PD, with a DCR of $69 \%$. As a first-line treatment, the ORR was 50\%, and the DCR was 75\% (2 CR, 4 PR, $1 \mathrm{SD}$, and1 PD); as a second-line treatment, the ORR was $33.3 \%$, and the DCR was 75\% (5 PR, $5 \mathrm{SD}$, and $2 \mathrm{PD}$ ); and as a third-line treatment, the ORR was $25 \%$, and the DCR was 58.3\% (2 PR, 6 SD, and 3 PD). The median PFS was 8.2 months, and the PFRs at three and six months were $81 \%$ and $69 \%$, respectively. The median OS was not achieved. Therapy with the combined treatment plus anlotinib maintenance resulted in an overall good response. Our findings showed obvious improvement of the PFS with the addition of anlotinib. However, another phase II trial showed that in 106 metastatic/advanced leiomyosarcoma, gemcitabine combined with pazopanib as secondline therapy, followed by pazopanib maintenance failed to meet its primary objective and was not beneficial for these patients. Moreover, there were significant toxicity, especially haematological adverse events during the combined treatment with gemcitabine and pazopanib. ${ }^{31}$ This toxicity diminished during the pazopanib monotherapy. Another phase Ib/II study of gemcitabine and docetaxel in combination with pazopanib for the neoadjuvant treatment of soft tissue sarcomas resulted in significant toxicity; despite pathologic responses, no objective responses occurred.
The trial was discontinued because of slow accrual after inclusion of five patients. ${ }^{32}$

Treatment tolerance and compliance are very critical issues. In our study, the most common grade 3 and 4 adverse events were febrile neutropenia (9\%), leukopenia $(19 \%)$, thrombocytopenia $(3 \%)$, anemia $(6 \%)$, anorexia $(6 \%)$, vomiting $(3 \%)$, and hypertension $(6 \%)$. The hematologic and non-hematologic toxicities were manageable and acceptable, and the incidence of toxicities was similar to that in a prior report of advanced STS chemotherapy. Most toxicities of combination therapy were reversible with appropriate medical management or dose reduction. No patients stopped treatment due to side effects. The toxicity of anlotinib maintenance therapy was mild, and the lipid metabolism and thyroid dysfunction were reversible. The manageable toxicity may allow its combination with conventional chemotherapy, ultimately leading to further improvements in advanced STS. Overall, in the lack of prospective clinical trials, the study confirms to some extent the value of anlotinib combined with chemotherapy in patients with advanced STS.

On the other hand, we need to recognize some limitations of the research. The main limitation is that the study was retrospective. In addition, the incidence rate of STS is relatively low, and the histological types are heterogeneous. Finally, this was a small-sample study.

\section{Conclusion}

In summary, we found that chemotherapy plus anlotinib combined with anlotinib maintenance is reliable, safe and feasible for advanced STSs. Ultimately, we also need to conduct a randomized and prospective trial to demonstrate the clinical benefits of chemotherapy in combination with anlotinib.

\section{Disclosure}

The authors report no conflicts of interest related to this work.

\section{References}

1. Sinha S, Peach AH. Diagnosis and management of soft tissue sarcoma. BMJ. 2010;341:c7170. doi:10.1136/bmj.c7170

2. Clark MA, Fisher C, Judson I, Thomas JM. Soft-tissue sarcomas in adults. N Engl J Med. 2005;353(7):701-711. doi:10.1056/NEJMra041866

3. Cesne AL, Bauer S, Demetri GD, et al. Safety and efficacy of pazopanib in advanced soft tissue sarcoma: PALETTE (EORTC 62072) subgroup analyses. BMC Cancer. 2019;19(1):794. doi:10.1186/s12885-019-5988-3

4. von Mehren M, Randall RL, Benjamin RS, et al. Soft tissue sarcoma, version 2.2016, NCCN clinical practice guidelines in oncology. $J$ Natl Compr Canc Netw. 2016;14(6):758-786. doi:10.6004/jnccn.2016.0078 
5. Mark L, Miah AB, Khin T, Judson IR, Charlotte B. Systemic treatment of soft-tissue sarcoma-gold standard and novel therapies. Nat Rev Clin Oncol. 2014;11(4):187. doi:10.1038/nrclinonc.2014.26

6. Tap WD, Papai Z, Van Tine BA, et al. Doxorubicin plus evofosfamide versus doxorubicin alone in locally advanced, unresectable or metastatic soft-tissue sarcoma (TH CR-406/SARC021): an international, multicentre, open-label, randomised Phase 3 trial. Lancet Oncol. 2017;18(8):1089-1103. S1470204517303819.

7. Sheng JY, Movva S. Systemic therapy for advanced soft tissue sarcoma. Surg Clin North Am. 2016;96(5):1141-1156. doi:10.1016/ j.suc.2016.06.006

8. Li F, Liao Z, Zhao J, et al. Efficacy and safety of apatinib in stage IV sarcomas: experience of a major sarcoma center in China. Oncotarget. 2017;8(38):64471-64480. doi:10.18632/oncotarget.16293

9. van der Graaf WT, Blay JY, Chawla SP, et al. Pazopanib for metastatic soft-tissue sarcoma (PALETTE): a randomised, double-blind, placebo-controlled phase 3 trial. Lancet. 2012;379(9829):1879-1886. doi:10.1016/S0140-6736(12)60651-5

10. Chi Y, Fang Z, Hong XN, Yao Y, Cai J. Safety and efficacy of anlotinib, a multikinase angiogenesis inhibitor, in patients with refractory metastatic soft tissue sarcoma. Clin Cancer Res. 2018;24 (21):5233-5238. clincanres.3766.2017.

11. Tawbi HA, Burgess $M$, Bolejack V, et al. Pembrolizumab in advanced soft-tissue sarcoma and bone sarcoma (SARC028): a multicentre, two-cohort, single-arm, open-label, Phase 2 trial. Lancet Oncol. 2017;18(11):1493-1501.

12. Lin B, Song X, Yang D, Bai D, Yao Y, Lu N. Anlotinib inhibits angiogenesis via suppressing the activation of VEGFR2, PDGFR $\beta$ and FGFR1. Gene. 2018;654:S0378111918301550. doi:10.1016/j. gene.2018.02.026

13. Sun Y, Wei N, Feng D, et al. Safety, pharmacokinetics, and antitumor properties of anlotinib, an oral multi-target tyrosine kinase inhibitor, in patients with advanced refractory solid tumors. J Hematol Oncol. 2016;9(1):105. doi:10.1186/s13045-016-0332-8

14. Xie C, Wan X, Quan H, et al. Preclinical characterization of anlotinib, a highly potent and selective vascular endothelial growth factor receptor-2 inhibitor. Cancer Sci. 2018;109(4):1207-1219. doi:10.11 11/cas.2018.109.issue-4

15. Yang S, Zhang Z, Wang Q. Emerging therapies for small cell lung cancer J Hematol Oncol. 2019;12(1):47. doi:10.1186/s13045-019-0736-3

16. Zhou AP, Bai Y, Song Y, et al. Anlotinib versus sunitinib as first-line treatment for metastatic renal cell carcinoma: a randomized phase II clinical trial. Oncologist. 2019;24(8):e702-e708. doi:10.1634/theoncologist.2018-0839

17. Han B, Li K, Zhao Y, et al. Anlotinib as a third-line therapy in patients with refractory advanced non-small-cell lung cancer: a multicentre, randomised phase II trial (ALTER0302). $\mathrm{Br}$ $J$ Cancer. 2018;118(5):654-661. doi:10.1038/bjc.2017.478

18. Sun Y, Du F, Gao M, et al. Anlotinib for the treatment of patients with locally advanced or metastatic medullary thyroid cancer. Thyroid. 2018;28(11):1455-1461. doi:10.1089/thy.2018.0022

19. Wenhong R, Borys K, Guy L, et al. Combined vascular endothelial growth factor receptor/epidermal growth factor receptor blockade with chemotherapy for treatment of local, uterine, and metastatic soft tissue sarcoma. Clin Cancer Res. 2008;14(17):5466. doi:10.11 58/1078-0432.CCR-08-0562
20. Sushil K, Reza Bayat M, Reihaneh S, et al. Metronomic oral topotecan with pazopanib is an active antiangiogenic regimen in mouse models of aggressive pediatric solid tumor. Clin Cancer Res. 2011;17 (17):5656-5667. doi:10.1158/1078-0432.CCR-11-0078

21. Hamberg P, Steeghs N, Loos WJ, et al. Decreased exposure to sunitinib due to concomitant administration of ifosfamide: results of a phase I and pharmacokinetic study on the combination of sunitinib and ifosfamide in patients with advanced solid malignancies. $\mathrm{Br}$ $J$ Cancer. 2010;102(12):1699. doi:10.1038/sj.bjc.6605696

22. Caicun Z, Yi-Long W, Gongyan C, et al. BEYOND: a randomized, double-blind, placebo-controlled, multicenter, Phase III Study of first-line carboplatin/paclitaxel plus bevacizumab or placebo in Chinese patients with advanced or recurrent nonsquamous non-smallcell lung cancer. J Clin Oncol. 2015;33(19):2197-2204. doi:10.1200/ JCO.2014.59.4424

23. Hurwitz H, Fehrenbacher L, Novotny W, et al. Bevacizumab plus irinotecan, fluorouracil, and leucovorin for metastatic colorectal cancer. $N$ Engl J Med. 2004;350(23):2335. doi:10.1056/NEJMoa03 2691

24. Escudier B, Bellmunt J, Négrier S, et al. Phase III trial of bevacizumab plus interferon alfa-2a in patients with metastatic renal cell carcinoma (AVOREN): final analysis of overall survival. J Clin Oncol. 2010;28(13):2144-2150. doi:10.1200/JCO.2009.26.7849

25. Oza AM, Cook AD, Pfisterer J, et al. Standard chemotherapy with or without bevacizumab for women with newly diagnosed ovarian cancer (ICON7): overall survival results of a phase 3 randomised trial. Lancet Oncol. 2015;16(8):928-936. doi:10.1016/S1470-2045(15)00086-8

26. Verschraegen CF, Arias-Pulido H, Lee S-J, et al. Phase IB study of the combination of docetaxel, gemcitabine, and bevacizumab in patients with advanced or recurrent soft tissue sarcoma: the axtell regimen. Ann Oncol. 2012;23(3):785. doi:10.1093/annonc/mdr299

27. Ryan CW, Merimsky O, Agulnik M, et al. PICASSO III: a Phase III, placebo-controlled study of doxorubicin with or without palifosfamide in patients with metastatic soft tissue sarcoma. J Clin Oncol. 2016;34:3898-3905. doi:10.1200/JCO.2016.67.6684

28. Schoffski P, Cornillie J, Wozniak A, Li H, Hompes D. Soft tissue sarcoma: an update on systemic treatment options for patients with advanced disease. Oncol Res Treat. 2014;37(6):355-362. doi:10.11 $59 / 000362631$

29. Shen G, Zheng F, Ren D, et al. Anlotinib: a novel multi-targeting tyrosine kinase inhibitor in clinical development. $J$ Hematol Oncol. 2018;11(1):120. doi:10.1186/s13045-018-0664-7

30. Muro XGD, Maurel J, Trufero JM, et al. Phase II trial of ifosfamide in combination with the VEGFR inhibitor sorafenib in advanced soft tissue sarcoma: a Spanish group for research on sarcomas (GEIS) study. Invest New Drugs. 2018;36(17):1-8. doi:10.1007/s10637-017-0500-x

31. Pautier P, Penel N, Ray-Coquard I, et al. A phase II of gemcitabine combined with pazopanib followed by pazopanib maintenance, as second-line treatment in patients with advanced leiomyosarcomas: a unicancer French Sarcoma Group study (LMS03 study). Eur j Cancer. 2020;125:31-37.

32. Munhoz RR, D’Angelo SP, Gounder MM, et al. A Phase Ib/II Study of gemcitabine and docetaxel in combination with pazopanib for the neoadjuvant treatment of soft tissue sarcomas. Oncologist. 2015;20 (11):1245-1246. doi:10.1634/theoncologist.2015-0245 


\section{Publish your work in this journal}

OncoTargets and Therapy is an international, peer-reviewed, open access journal focusing on the pathological basis of all cancers, potential targets for therapy and treatment protocols employed to improve the management of cancer patients. The journal also focuses on the impact of management programs and new therapeutic agents and protocols on patient perspectives such as quality of life, adherence and satisfaction. The manuscript management system is completely online and includes a very quick and fair peer-review system, which is all easy to use. Visit http://www.dovepress.com/ testimonials.php to read real quotes from published authors.

Submit your manuscript here: https://www.dovepress.com/oncotargets-and-therapy-journal 